\title{
Potential of $10 \%$ strawberry gel (fragaria $x$ annanassea) as an alternative bleaching agent for extrinsic discoloration of composite resin: an in vitro study
}

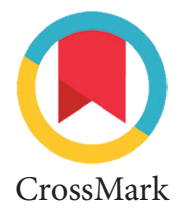

\author{
Mariska Juanita, Christine A. Rovani,, Indrya K. Mattulada, Maria Tanumihardja
}

\section{Abstract}

Objective: The aim of this study was to examine the potential of $10 \%$ strawberry gel in reducing extrinsic discoloration of composite resin. Material and Methods: This was a laboratory experimental study using 40 composite resins molded in 8-mm diameter and 2$\mathrm{mm}$ thickness. Samples were soaked in coffee solution for 7 days to obtain discoloration and checked by VITAPAN classical囚shade guideand adobe photoshop CS4 Version 11.0 by CIEL ${ }^{*}{ }^{*} b$ method. The discolored samples were randomly divided into two groups of 20 samples of each group. Group I was treated with 10\% strawberry gel for 8 hours every day in 12 consecutive days and group II as control group was treated with $10 \%$ carbamide peroxide in the same way as group 1 .

Results: The results showed a significant change of the color in each group according to Friedman test $(p<0.05)$ while no significant color change difference of group I when compared to group II based on the results of Mann-Whitney test. Either 10\% strawberry gel or $10 \%$ carbamid peroxide could not return the composite resins color into the baseline.

Conclusion: $10 \%$ strawberry gel has similar potency as $10 \%$ carbamid peroxide in reducing extrinsic discoloration of composite resin.

Keywords: 10\% Strawberry gel, Bleaching agent, Composite resin, Extrinsic discoloration

Cite this Article: Juanita M, Rovani CA, Mattulada IK, Tanumihardja M. 2019. Potential of $10 \%$ strawberry gel (fragaria $x$ annanassea) as an alternative bleaching agent for extrinsic discoloration of composite resin: an in vitro study. Journal of Dentomaxillofacial Science 4(1): 22-27. D0I:10.15562/jdmfs.v4i1.832

Department of Conservative Dentistry, Faculty of Dentistry, Hasanuddin University, Makassar, Indonesia
*Correspondence to: Christine A. Rovani, Department of Conservative, Faculty of Dentistry, Hasanuddin University, Makassar, Indonesia

ch_rovani@yahoo.com

Received: 29 0ctober 2018 Revised: 19 February 2019 Accepted: 5 March 2019 Available Online 1 April 2019

\section{Introduction}

Composite resins have been one of the most popular materials in aesthetic dentistry because of their excellent aesthetic properties and adequate strength. Aesthetic restorative materials should mimic the appearance of the natural tooth in both color match and color stability. However, restorative resin composites have a tendency to discolor in the oral environment due to intrinsic or extrinsic factors. ${ }^{1,2}$ Intrinsic discoloration are defined as change in the resin matrix or at the matrix/filler interface while extrinsic factors include staining due to superficial or deep absorption of colorants because of contamination from external sources.

Degree of external color change varies from patient to patient based on oral hygiene status, nutritional habits, lifestyle and cigarette smoking. ${ }^{2}$ These discolorations are the primary reason for replacing composite-resin restorations that tend to increase the preparation and restoration size which may eventually lead to destruction of the remaining tooth structures called 'restoration death spiral'. ${ }^{1}$ Thus alternative approaches were developed to minimize the loss of healthy dental tissue (minimal invasive approach). ${ }^{3,4}$

Bleaching is one of the alternative approaches to reduce discolored composite resin restoration by the application of bleaching agent. ${ }^{5}$ Carbamide peroxide (CP) or hydrogen peroxide (HP) has been commonly used as bleaching agent that is able to provide tooth color change and at the same time may yield color alterations of composite resin restorations. ${ }^{6,7}$ Pruthi et al. ${ }^{7}$ stated a significant color change was observed on composite resin and GIC restorations following aplication of $10 \%$ carbamide peroxide. ${ }^{8}$ Some other studies also reported color change of composite resin restoration following application of natural ingredients including tomatoes, calamandin, and strawberries.

Strawberry (fragraria $\mathrm{x}$ annanasea) is one of many fruits that can be used as natural bleaching agent. Margaretha et al. ${ }^{11}$ reported the significant effect of strawberry juice on the brightness of enamel and restoration in composite resin-restored teeth. However high acidity of strawberry juice has become a concern that can affect roughness of the restoration. Addition of carbopol and triethanolamine (TEA) as gelling agent could be proposed to increase the $\mathrm{pH} .{ }^{11,12}$ Therefore this study is aimed to examine the potential of strawberry fruits formulated into gel to be used as an alternative bleaching agent for extrinsic discoloration of dental composite resin. ${ }^{11,12}$

\section{Material and Methods}

\section{Collection and preparation of the material}

The preparation of the material was done into 2 parts.

First part: strawberry fruits collected from high- 
land region of Malino, South Sulawesi, Indonesia, were rinsed with water, cut in a half, and extracted by maceration method. The extract was mixed with prophylene glycol and formulated to prepare $10 \%$ strawberry gel.

\section{Sample preparation}

Forty samples were fabricated from nanofilled composite resin (Filtek TM Z350 XT shade A3, 3M ESPE, USA) using a plastic mold of 8-mm diameter and 2-mm thickness. Samples were light-cured for 20 seconds on each side at $1 \mathrm{~mm}$ distance using LED light curing unit with light intensity $1500 \mathrm{~mW} /$ cm2 (Liang Ya Dental Equipment Co. Ltd LY-B200, Guangzhou). The samples were placed in distilled water at $37^{\circ} \mathrm{C}$ for 24 hours to ensure complete polymerization, and thenwere randomly divided into two groups of 20 samples each, soaked in coffee solution for 7 days. Group I was applied with 10\% strawberry gel for 3 minutes and group II as control group was applied with $10 \%$ carbamide peroxide for 3 minutes (Opalescence PF®, Ultradent Products Inc, USA). Samples of both groups werekept for 8 hours, rinsed with water, dried and put them into a plastic container. The procedures were repeated in 12 consecutive days.

\section{Color assesment}

The color of all samples were analysed using VITAPAN Classical® Shade Guide (Vita Zahnfabrik H.Rauter $\mathrm{GmbH}$ \& Co KG, Bad sckingen, Germany) and Adobe Photoshop CS4 Version 11.0 (Adobe Systems, USA) by CIEL*a*b (Commission Internationale de I'Eclairage $\mathrm{L}^{*}, \mathrm{a}^{*}, \mathrm{~b}^{*}$ ) method. Color was observed and determined at baseline (before treatment), after soaking in coffee solution for 7 days,and after treating with 10\% strawberry gel and bleaching agent on day 3, 6, 9 and 12.Color change (E) was calculated by the equation below

$$
\begin{gathered}
\Delta \mathrm{E}=\left[\left(\Delta \mathrm{L}^{*}\right)^{2}+\left(\Delta \mathrm{a}^{*}\right)^{2}+\left(\Delta \mathrm{b}^{*}\right)^{2}\right]^{1 / 2} \text { or } \\
\Delta \mathrm{E}=\sqrt{\left(\mathrm{L}_{2}^{*}-\mathrm{L}_{1}^{*}\right)^{2}+\left(\mathrm{a}_{2}^{*}-\mathrm{a}_{1}^{*}\right)^{2}+\left(\mathrm{b}_{2}^{*}-\mathrm{b}_{1}^{*}\right)^{2}}
\end{gathered}
$$

The color space consists of three coordinates $\mathrm{L}^{*}, \mathrm{a}^{*}$ and $b^{*}$. The $L^{*}$ refers to the lightness coordinate and its value ranges from 0 for perfect black to 100 for perfect white. The $\mathrm{a}^{*}$ and $\mathrm{b}^{*}$ are the chromaticity coordinates in the green-red axis and the blue-yellow axis, respectively. Negative $\mathrm{a}^{*}$ values cover the green color range and negative values indicate red color range. Similarly, negative $b^{*}$ values indicate blue color range while positive values indicate yellow color range.
$\Delta \mathrm{E}$ shows difference in color value of samples before treatment $\left(\mathrm{L}_{1}{ }_{1}, \mathrm{a}_{1}{ }_{1}, \mathrm{~b}_{1}{ }_{1}\right)$ in comparison with $L_{2}^{*}, a_{2}{ }_{2}, b_{2}^{*}$ value of samples after treatment. Thus six $\mathrm{E}$ were obtained from this method: a. $\triangle \mathrm{E} 1$ (after soaking in coffee solution - baseline); b. $\Delta \mathrm{E} 2$ (day 3 after treatment - after soaking in coffee solution); c. $\Delta \mathrm{E} 3$ (day 6 - day 3 after treatment); d. $\Delta \mathrm{E} 4$ (day 9 - day 6 after treatment); e. $\Delta \mathrm{E} 5$ (day 12 -day 9 after treatment); f. $\Delta$ E6 (day 12 after treatment - baseline).

$\Delta \mathrm{E}$ value $<1$ is considered not visible to the naked eye. A perceptible discoloration, that is $\Delta \mathrm{E}$ $>1.0$ is acceptable up to the value of $\Delta \mathrm{E}=3.3$ in subjective visual evaluations under optimal lighting conditions. A value E 3.3 is considered clinically acceptable in the study.

\section{Statistical analysis}

The results of color difference of each observation time of each group were analyzed by Friedman tests. The comparison of color change evaluation ofboth groupat each observation timewas analyzed by Mann-Whitney test. For both tests, the level of significance was $5 \%$.

\section{Results}

Table 1 showed E1 mean value in samples of group I was higher than 3.3 after soaking in coffee solution for 7 days $(\Delta \mathrm{E} 1: 9.91 \pm 1.65)$. Following treatment with $10 \%$ strawberry gel, the value lower than 3.3 was observed on day $6(\Delta \mathrm{E} 3: 3.18 \pm 1.82)$ and on day $12(\Delta \mathrm{E} 5: 0.37 \pm 0.18)$.

Color change difference on day 12 after treatment with $10 \%$ strawberry gel compared with baseline color was also lower than 3.3 as seen in table 1 for group I $(\Delta \mathrm{E} 62.79 \pm 1.60)$. In group II E1 mean value was also higher than 3.3 after soaking in coffee solution for 7 days $(\Delta \mathrm{E} 1: 10.48 \pm 1.41)$. Following bleaching with $10 \%$ carbamide peroxide, the value lower than 3.3 was observed on day $6(\Delta \mathrm{E} 3: 2.47 \pm 1.24)$ and on day $12(\Delta \mathrm{E} 5: 0.29 \pm 0.12)$.

Comparison of color change difference on day 12 after bleaching and baseline was also lower than 3.3 as seen in table 1 for group II $(\Delta \mathrm{E} 62.39 \pm 1.92)$. A significant change to lighter color was observed in each group after 12 days observation (p:0.000).

Table 2 showed color change difference value of group I was significantly lower than group II on day $3(\Delta \mathrm{E} 2)(\mathrm{p}=0.017)$ and day $9(\Delta \mathrm{E} 4)(\mathrm{p}=0.015)$. however the color difference value was still in clinically acceptable value, which is lower than 3.3.

The changes in the mean lightness and chromaticity coordinate $\left(\Delta \mathrm{L}^{*}, \Delta \mathrm{a}^{*}, \Delta \mathrm{b}^{*}\right)$ are presented 
Table 1 Mean of color change difference value $(\Delta E)$ of each observation time of each group

\begin{tabular}{|c|c|c|c|c|c|c|c|c|}
\hline \multirow[b]{2}{*}{ Group } & \multirow[b]{2}{*}{$n$} & \multicolumn{6}{|c|}{$\Delta \mathrm{E}$} & \multirow[b]{2}{*}{$p$-value } \\
\hline & & $\begin{array}{c}\Delta \mathrm{E} 1 \\
\text { Mean士SD }\end{array}$ & $\begin{array}{c}\Delta E 2 \\
M e a n \pm S D\end{array}$ & $\begin{array}{c}\Delta \mathrm{E3} \\
M e a n \pm S D\end{array}$ & $\begin{array}{c}\Delta \mathrm{E} 4 \\
\text { Mean } \pm \text { SD }\end{array}$ & $\begin{array}{c}\Delta \mathrm{E} 5 \\
\text { Mean } \pm \text { SD }\end{array}$ & $\begin{array}{c}\Delta \mathrm{E} 6 \\
M e a n \pm S D\end{array}$ & \\
\hline I & 20 & $9.91 \pm 1.65$ & $4.73 \pm 1.33$ & $3.18 \pm 1.82$ & $3.78 \pm 1.50$ & $0.37 \pm 1.50$ & $2.79 \pm 1.60$ & $0.000^{\star}$ \\
\hline II & 20 & $10.48 \pm 1.41$ & $6.25 \pm 1.77$ & $2.47 \pm 1.24$ & $4.86 \pm 1.22$ & $0.29 \pm 0.12$ & $2.39 \pm 1.92$ & $0.000^{*}$ \\
\hline
\end{tabular}

aNormality test, Shapiro-Wilk test: $\mathrm{p}<0.05$; data distribution not normal

*Friedman test: $\mathrm{p}<0.05$, Significant

Table 2 Color change difference value $(\Delta \mathrm{E})$ between groups at each observation time

\begin{tabular}{|c|c|c|c|c|c|c|c|}
\hline \multirow[b]{2}{*}{ Group } & \multirow[b]{2}{*}{$n$} & \multicolumn{5}{|c|}{$\Delta \mathrm{E}$} & \multirow[b]{2}{*}{$\begin{array}{c}\Delta \mathrm{E} 6 \\
\text { Mean } \pm \text { SD }\end{array}$} \\
\hline & & $\begin{array}{c}\Delta E 1 \\
M e a n \pm S D\end{array}$ & $\begin{array}{c}\Delta \mathrm{E} 2 \\
\text { Mean } \pm \text { SD }\end{array}$ & $\begin{array}{c}\Delta \mathrm{E} 3 \\
M e a n \pm S D\end{array}$ & $\begin{array}{c}\Delta \mathrm{E} 4 \\
\text { Mean士SD }\end{array}$ & $\begin{array}{c}\Delta \mathrm{E} 5 \\
\text { Mean士SD }\end{array}$ & \\
\hline I & 20 & $9.91 \pm 1.65$ & $4.73 \pm 1.33$ & $3.18 \pm 1.82$ & $3.78 \pm 1.50$ & $0.37 \pm 1.50$ & $2.79 \pm 1.60$ \\
\hline \multirow[t]{2}{*}{ II } & 20 & $10.48 \pm 1.41$ & $6.25 \pm 1.77$ & $2.47 \pm 1.24$ & $4.86 \pm 1.22$ & $0.29 \pm 0.12$ & $2.39 \pm 1.92$ \\
\hline & & 0.234 & $0.017^{*}$ & 0.394 & $0.015^{\star}$ & 0.261 & 0.957 \\
\hline
\end{tabular}

aNormality test, Shapiro-Wilk test: $\mathrm{p}<0.05$; data distribution not normal

*Mann-Whitney test: $\mathrm{p}<0.05$; significant

Table 3 Mean of $\Delta \mathbf{L}^{*}, \Delta \mathbf{a}^{*}, \Delta \mathbf{b}^{*}$ value of each observation time of each group

\begin{tabular}{lllllll}
\hline Mean & $\boldsymbol{\Delta} \mathbf{L}$ & $\begin{array}{c}\text { Group I } \\
\mathbf{\Delta} \mathbf{a}\end{array}$ & $\mathbf{\Delta} \mathbf{b}$ & $\mathbf{\Delta} \mathbf{L}$ & $\begin{array}{c}\text { Group II } \\
\mathbf{\Delta a}\end{array}$ & $\mathbf{\Delta b}$ \\
\hline$\Delta \mathrm{E} 1$ & 10.445 & -0.0695 & 0.31475 & 9.185 & 0.0075 & 0.348 \\
$\Delta \mathrm{E} 2$ & -5.4925 & 0.715 & -2.804 & -4.1365 & 0.716 & -1.3517 \\
$\Delta \mathrm{E} 3$ & -2.179 & -0.3485 & 0.0185 & -2.106 & -0.2502 & -1.0964 \\
$\Delta \mathrm{E} 4$ & -1.2745 & 0.0102 & 3.9305 & -2.099 & 0.2648 & 1.9835 \\
$\Delta \mathrm{E} 5$ & -0.0885 & -0.0167 & -0.0405 & -0.0012 & -0.0468 & -0.001 \\
\hline
\end{tabular}
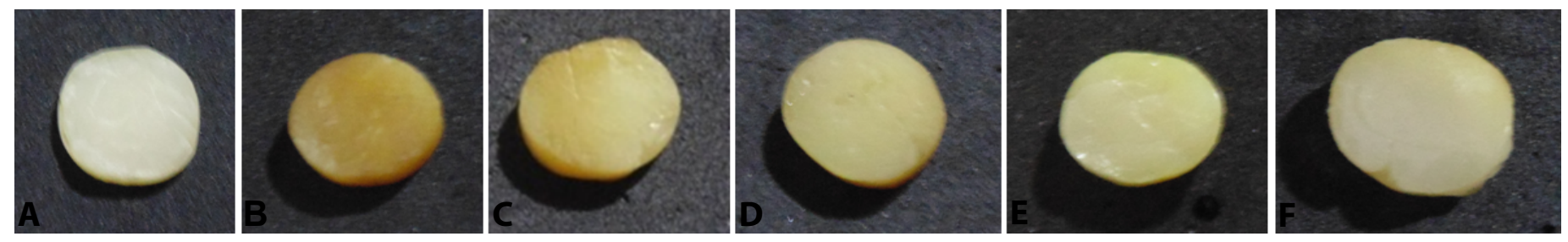

Figure 1 Visual composite resin's shade: A. Baseline, B. After soaking in coffee solution, C-F. After treatment with $10 \%$ strawberry gel on day 3, day 6 , day 9 , and day 12 . It was observed that $10 \%$ strawberry gel could lighten the composite resins color although it could not return the color lightness into baseline.

in table 3 and figure 3-5. The lightness values in $\Delta \mathrm{L}^{*}$ showed an increase for both groups, while the mean $\Delta \mathrm{a}^{*}$ values were relatively unstable and no observable change in the red-green chromaticity coordinate as seen in figure 4 although both groups almost return to baseline despite fluctuation of $\Delta \mathrm{a}^{*}$ values. These was also observed for $\Delta b^{*}$ values in figure 5. Data from our study indicates that changes in $\Delta \mathrm{E}$ values were primarily due to changes in $\Delta \mathrm{L}^{*}$ values. 

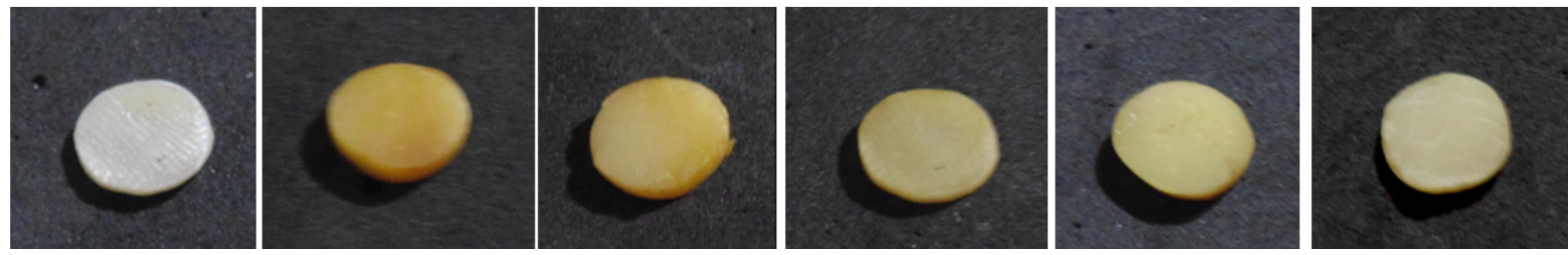

Figure 2 Visual composite resin's shade: a) baseline; b) after soaking in coffee solution; c-f) after bleaching with $10 \%$ carbamide peroxide on day 3 , day 6 ,day 9 , and day 12 . It was observed that $10 \%$ carbamide peroxide could lighten the composite resins color although it could not return the color brightness into baseline.

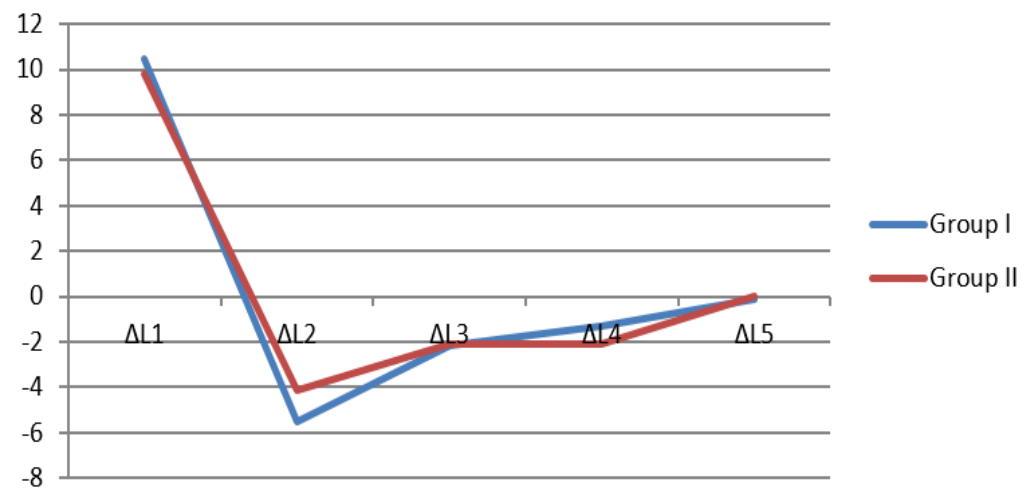

Figure 3 Changing of $\Delta \mathrm{L}^{*}$ value during each observation time of each group

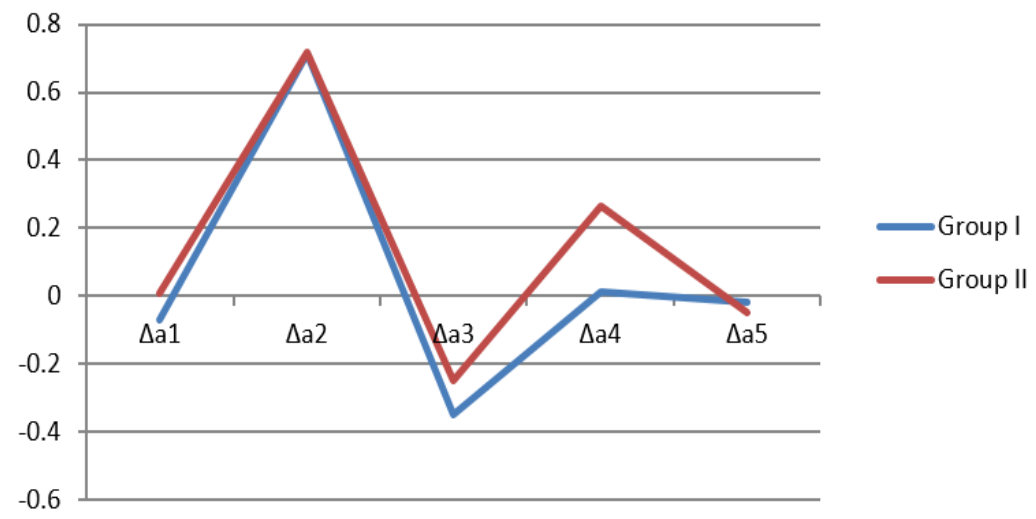

Figure 4 Changing of $\Delta \mathrm{a}^{*}$ value during each observation time of each group

\section{Discussion}

Color is a complex phenomenon and its perception is influenced by lighting conditions, translucency, opacity, light scattering, and the human eye, therefore it may be reported differently on different occasions. ${ }^{1,7,8}$ Two methods is usually used to evaluate the color; vitapan for visual color assessment and CIE L $\mathrm{a}^{*} \mathrm{~b}^{*}$ method $(\Delta \mathrm{E})$ which is also well suited for determination of slightly color differences.

Excellent aesthetics is of utmost important for tooth-colored materials to maintain their intrinsic color stability and resistance to surface staining. However, composite restorations acquire external stains when exposed to saliva, stains, food components, and beverages in the oral environment that can affect the esthetic quality of composite restorations. ${ }^{9}$ Drinking coffee is a trending lifestyle nowadays and studies showed coffee discolors composite restorations much than tea and cola. ${ }^{15,16}$ Therefore coffee solution was chosen to discolor the samples in this study which showed perceptible color changes $\left(\Delta \mathrm{Eab}^{*} \geq 3.3\right)$ following 7 days immersion. Yellow colorants contained in coffee is assumed to induce visible discoloration of composite resin.

External bleaching is one of many approaches to improve dental esthetics by reducing such discoloration and lead restoration to lighter color. ${ }^{5}$ That $10 \%$ carbamide peroxide can remove stain on the surface of composite resins and hybrid ionomer, however tooth sensitivity and gingival irritation can occur in some patients, although in most cases they are mild to moderate and transient. Natural bleaching materials were reported to have whitening potentials including tomatoes, strawberries, and calamondin.

Strawberry juice effectively lighten tooth enamel color after soaking it for 3 hours. It is proposed that high acidity of strawberry juice with $\mathrm{pH}$ value $3-4$ is one of the factors in whitening the teeth. However this low $\mathrm{pH}$ tends to increase the surface roughness of the restorations causing them to pick-up stains more readily after bleaching. Therefore the $\mathrm{pH}$ in this study was increased by formulating to strawberry gel, and color change was also observed following treatment with $10 \%$ strawberry gel. This could be explained by the presence of ellagic acid and malic acid contained in strawberry (fragraria $\mathrm{x}$ annanasea). The acids penetrate the organic matrix and release electron by oxidation process that cause chromo- 


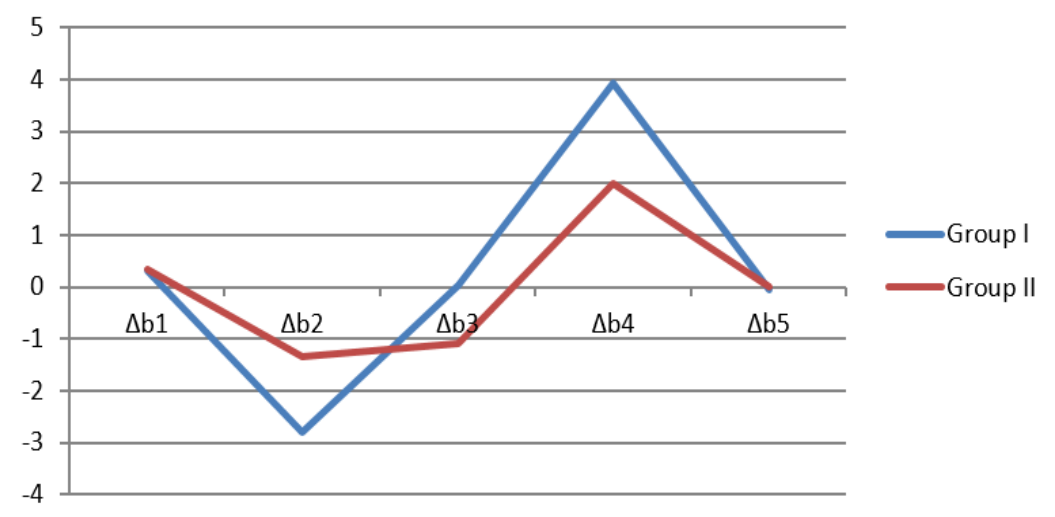

Figure 5 Changing of $\Delta b^{*}$ value during each observation time of each group

gen degradation on the surface of composite resin which lead the composite resin into a lighter color. ${ }^{10,11}$ In addition, high level of ellagic acid produces more potential $\mathrm{OH}$ clusters which break and produce $\mathrm{H}+$ radical as a powerful oxidizer thus make bleaching process more effective. In this study treatment with $10 \%$ strawberry gel showed similar significant color change with $10 \%$ carbamide peroxide for each observation time $(\mathrm{p}<0.05)$. On the other hand, color change difference between groups was not significantly different at each observation time. This result was in line with the results reported by Margaretha et al. ${ }^{12}$ that no significant of color change difference on teeth following immersion in strawberry juice and $10 \%$ carbamide peroxide for 2 weeks time. $^{12}$

Both $10 \%$ strawberry gel and $10 \%$ carbamide peroxide could not return the samples' color into baseline color. This may be explained by the presence of bisphenol A diglycidyl methacrylate (Bis-GMA), and triethylene glycol dimethacrylate (TEGDMA) as hydrophilic monomer in composite resin that may be more susceptible to water sorption and discoloration over time. When each component of CIE L*a* $\mathrm{b}^{*}$ method was analyzed, it was shown that the color of all samples became lighter $(\Delta \mathrm{L})$ following treatment with both $10 \%$ strawberry gel and $10 \%$ carbamide peroxide (diagram I). In contrast, both $\Delta \mathrm{a}$ (represent greenred color) and $\Delta \mathrm{b}$ (represent yellow-blue color) showed lack of changes (diagram II and III). This might be assumed that bleaching agent si only able to lighten the color of the samples. That $15 \%$ hydrogen peroxide could only lighten the discolored of composite resin into resemble baseline color. This could be related to camphorquinone (CQ) used as photo initiator in dental composite resin. Camphorquinone is a solid yellow compound with an unbleachable chromophore group, which might explain all samples' color could not return into baseline color. $45 \%$ hydrogen peroxide could reduce discoloration into baseline color in 14 days. Further studies need to be carried out to evaluate the potency of strawberry gel in higher concentration.

\section{Conclusion}

Under the limitation of this study, it can be concluded that $10 \%$ strawberry gel has similar potency as $10 \%$ carbamid peroxide to reduce extrinsic discoloration of composite resin.

\section{Acknowledgment}

The authors are extremely grateful to Head and staff of Phytopharmaca Laboratory and Pharmaceutical Laboratory in Faculty of Pharmacy Hasanuddin University for their assistance in carrying out this study. All authors have made substantial contributions to the work reported in the manuscript. Christine A. Rovani, Indrya K. Mattulada, Maria Tanumihardja: Conception and designing of the study, drafting the article, critical revision of the article, final approval of the study to be published. Mariska Juanita contribute for carrying out the study, data collection, data analysis and interpretation, drafting the article.

\section{Conflict of Interest}

The authors report no conflict of interest.

\section{References}

1. Barutcigil C, Yildiz M. Intrinsic and extrinsic discoloration of dimethacrylate and silorane based composites. J Dentist 2012;40: 57-63.

2. Zajkani E, Tabrizi MA, Ghasemi A, et al. Effect of staining solutions and repolishing on composite resin color change. JIDAI 2013;25: 83-90.

3. Fejerskov O, Kidd E. Dental caries: the disease and its clinical management. Oxford: Blackwell Munksgaard Ltd.; 2009. p. 444.

4. Moncada G, Fernandez E, Martin J, et al. Increasingthe longevity of restorations by minimal intervention: a two year clinical trial. Open Dent 2008;33: 258-264.

5. Wang L, Fransisconi LF, Atta MT, et al. Effect of bleaching gels on surface roughness of nanofilled composite resins. Europ J Dentist 2011;5: 173-179.

6. Amedee AA, Ragab H, Salameh Z, et al. Evaluation the effect of in-office bleaching on color changes on restorative composite resins. IJSR 2013;2: 224-228.

7. Pruthi G, Jain V, Kandpal HC, et al. Effect of bleaching on colorchange and surface topography of composite restorations. Int J Dentist 2010: 1-7.

8. Li Y, Greenwall L. Safety issues of tooth whitening using peroxide-basedmaterials. British Dent J 2013;215: 29-34. 
9. Larasati DM, Firsty KN, Yogiartono M. Effectiveness of ellagic acid thatcontains in strawberry for acrylic discoloration. Asia Pacific Dent Students J 2012;3: 3-9.

10. Das S, Haldar PK, Pramanik G. Formulation and evaluation of herbal gel containing clerodendron infortunatum leaves extract. Int J Pharm Res 2011;3: 140-143.

11. Margaretha J, Rianti D, Meizarini A. Effect ofstrawberry paste and carbamide perokside gel $10 \%$ towards the brightnessenamel tooth. Material Dent J 2009;1: 16-20.
12. Xu B, Li Q, Wang Y. Effect of $\mathrm{pH}$ values of hydrogen peroxide bleaching agentson enamel surface properties. Operat Dentist 2011;36: 554-562.

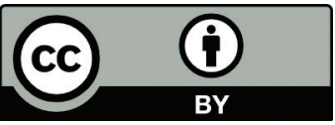

This work is licensed under a Creative Commons Attribution 